University of Nebraska - Lincoln

DigitalCommons@University of Nebraska - Lincoln

Faculty Publications: Department of Teaching, Department of Teaching, Learning and Teacher Learning and Teacher Education

Education

2013

Acknowledging the Religious Beliefs Students Bring Into the Science Classroom: Using the Bounded Nature of Science

Sherry A. Southerland

Lawrence C. Scharmann

Follow this and additional works at: https://digitalcommons.unl.edu/teachlearnfacpub

Part of the Curriculum and Instruction Commons, and the Teacher Education and Professional

Development Commons

This Article is brought to you for free and open access by the Department of Teaching, Learning and Teacher Education at DigitalCommons@University of Nebraska - Lincoln. It has been accepted for inclusion in Faculty Publications: Department of Teaching, Learning and Teacher Education by an authorized administrator of DigitalCommons@University of Nebraska - Lincoln. 


\title{
Acknowledging the Religious Beliefs Students Bring Into the Science Classroom: Using the Bounded Nature of Science
}

\author{
Sherry A. Southerland \& Lawrence C. Scharmann \\ Florida State University \\ Correspondence - Sherry A. Southerland, School of Teacher Education, Florida State University, \\ G119 Stone, Tallahassee, FL 32306-4459, USA; email ssoutherland@fsu.edu
}

\begin{abstract}
Scientific knowledge often appears to contradict many students' religious beliefs. Indeed, the assumptions of science appear contradictory to the metaphysical claims of many religions. This conflict is most evident in discussions of biological evolution. Teachers, in attempts to limit the controversy, often avoid this topic or teach it superficially. Recently, there has been a political effort to teach to the controversy-which some see as a way of introducing religious explanations for biological diversity into science classrooms. Many science educators reject this approach, insisting that teachers limit classroom discussions to science alone. This science only approach leaves the negotiation of alternative knowledge frameworks to students, who are often ill-prepared for such epistemological comparisons. To support students' understanding of science while maintaining their religious commitments, this article explores the utility of emphasizing the boundaries of scientific knowledge and the need to support students in their comparison of contradictory knowledge frameworks.
\end{abstract}

Published in Theory Into Practice, 52 (2013), pp 59-65.

DOI: $10.1080 / 07351690.2013 .743778$

Copyright (c) 2013 The College of Education and Human Ecology, The Ohio State University; published by Routledge/Taylor \& Francis. Used by permission.

Sherry A. Southerland is a professor and co-director of FSU-Teach, and Lawrence C. Scharmann is an assistant dean and director of the School of Teacher Education. [Dr. Scharmann is currently (2020) at the University of Nebraska-Lincoln.] 
W

hen one thinks of science teaching in terms of student diversity, a number of thoughts come to mind: English language learners, race, ethnicity, exceptionalities, socioeconomic status. Indeed, when one examines the policies (e.g., No Child Left Behind Act, 2001) designed to close academic achievement gaps or the research conducted to understand student learning, these are key demographic variables through which student diversity is considered. The focus of our article, however, is to examine an often ignored aspect of who students are as human beings-their religious beliefs-to understand what role beliefs that are seemingly contradictory to science can have in shaping students' science learning, and to describe the role that the bounded nature of science can play in helping students navigate that contradiction.

\section{Religion, Science Classrooms, and the Nature of Science}

\section{Religiously Speaking, Who Are We Teaching in Science Class?}

In preparing for this article, we sought information on the religious traditions of students in the public schools in the United States. Interestingly enough, that information could not be found. Although each state, as well as the federal government, systematically tracks multiple student diversity variables in public schools, religious diversity is not included in these data. Instead, we resorted to the Pew Forum (2008), which tracks the religious traditions of a sampling of Americans 18 years or older, in the hopes that these data would shed some light on the religious breakdown of students in American schools. The Pew Forum reported that "religious affiliation in the US is both very diverse and extremely fluid" (p. 5). Fifty-one percent of respondents were members of a Protestant faith, whose individual denominations can be grouped into three broad categories-evangelical Protestant churches (26.3\% of the overall adult population), mainline Protestant churches (18.1\%), and historically Black Protestant churches (6.9\%). The second most populated faith was the Catholic Church with $23.9 \%$ of all adults, followed by unaffiliated individuals (16.1\%). In addition to these three traditions, the United States includes $1.7 \%$ LatterDay Saints, 1.7\% Jews, 0.7\% Buddhists, 0.6\% Muslims, 0.6\% Greek Orthodox, and $0.4 \%$ Hindus. 


\section{Difference Blindness and Science Teaching}

Perhaps it is not coincidental that information on the religious affiliation of US students cannot be easily located. In the United States, there has been a long history of separation of religious beliefs from the public school curriculum, a separation that stems from the First Amendment's prohibition of government in establishing religion or religious practices in the public sphere.

Even though policy is clear that the classroom is not a place in which religious practices are to be cultivated, should a student's religious faith matter when one considers learning-particularly science learning? The answer to this question seems obvious to the many teachers who employ difference blindness in their teaching (Southerland, Smith, Sowell, \& Kittleson, 2007). As a broad form of colorblindness (Cochran-Smith, 1995), difference blindness is the notion that what matters in teaching is the individual student, rather than the student's membership in various demographic subgroups. Teachers who practice difference blindness claim to be unwilling to recognize differences caused by a student's background, culture, etc. From this perspective, students' ethnicity, race, socioeconomic status, gender, and religion are simply not issues for teachers to consider. Such teachers often embrace the response to the individual in their teaching and reject the utility of considering how groups of students may be reacting to course material (Southerland, Gallard, \& Callihan, 2011). As one science teacher in our past research has described, "[A student's] ethnicity, disabilities, economic status should all be left at the classroom door" (Southerland et al., 2011, p. 21). If teachers ignore these more visible qualities in their difference blindness, then they would likely argue that any consideration of religion should also be left at the classroom door.

What is the danger of difference blindness? When teachers fail to recognize the differences our students bring with them into the classroom, the habits/prior knowledge/beliefs of mainstream students and teachers are understood to be the norm (Cochran-Smith, 1995; Southerland et al., 2007). If the cultural knowledge, habits of mind, and religious commitments of teachers, school administrators, and textbook authors become accepted as the standard, then all deviations are either ignored or devalued. This failure to acknowledge students' differences limits teachers' recognition that all students have a wealth of 
knowledge, values, beliefs, attitudes, and ways of looking at the world developed in their home lives. Using difference blindness as a filter, students are urged to engage with and accept school knowledge even when it seemingly conflicts with their deeply personal, culturally embedded knowledge.

The embrace of difference blindness by many science teachers is particularly defeating when one considers the factors that influence an individual's learning. "The research community has recognized what science teachers have long known, that a learner's affect and emotions significantly influence the learning that can occur" (Southerland, Golden, \& Enderle, 2011, p. 82). A wide body of research has demonstrated that a learner's prior knowledge-her view of scientific knowledge (sure or tentative), her reactions to contradictory evidence, her willingness to wrestle with a complex issue, her view of her capability as a science learner, and even (or in some cases especially) her emotions surrounding an aspect of science-play an important role in shaping what the individual can learn in a classroom. To ignore who a student is (meaning to ignore what she knows, believes, and feels) is to ignore the many factors that must be considered to effectively teach science to the student. Who wants to become actively engaged in a community or classroom that ignores much of what is personally important? On a broader level, the failure to acknowledge students' religious beliefs may also undermine the public education's commitment to diversity.

\section{Religious Commitments and Science Learning}

Indeed, we argue that a student's religious commitments may be one of the most salient factors that teachers should consider as they approach their science curriculum. The origins of life, the creation of the universe, climate change, biological evolution, and particularly the evolution of Homo sapiens are well accepted as appropriate discussions in the scientific community. Each of these constructs, however, can cause some controversy in the science classroom, as these ideas often evoke a perception of conflict with a student's religious beliefsbroader frameworks they have developed to understand the world and frameworks they often share with their families, their places of worship, and their broader cultural communities. 
Although the research is divided in terms of the influence that students' belief or disbelief plays on their understanding of a science concept (see Nadelson \& Southerland, 2010, for a more full discussion), the research is clear on the influence of this debate on teaching: Teachers avoid addressing controversial issues in their classrooms. This avoidance can best be documented in teachers' approaches to evolution in the classroom. Aguillard (1999) described that 6o\% of Louisiana's teachers spend less than 5 days teaching evolution, and this is echoed throughout the nation (Scott \& Branch, 2006). Dean (2005) described that some teachers in Alabama assign the chapter on evolution to their students, without discussing the topic; others simply fail to even assign the chapter. This avoidance could be due to teachers' own discomfort with evolution or to their fear of the students' reactions to this material when teachers are hobbled by difference blindness - that is, their failure to recognize the need to provide support for students who find evolution contradictory with their beliefs. The interaction of personal discomfort, fear of classroom reactions, and difference blindness may explain why so many Americans fail to understand this concept, despite its importance to a fundamental understanding of all of biology (Alters \& Alters, 2001) and this interaction also act to prevent students with religious beliefs counter to mainstream science from receiving a robust science education.

\section{Effective and Equitable Approaches to the Teaching of Science}

\section{Having Students Consider What Counts as Science}

One of the central tenants of an equitable approach to science teaching is that teachers need to help students become explicitly aware of what counts as valid in a science classroom. That is, equitable science teaching should engage students in an explicit focus on the ways of talking and writing that are valued in science (Moje, Collazo, Carrillo, \& Marx, 2001). Along with emphasizing these discursive practices, we suggest that equitable science teaching should also have an epistemological focus-science teachers should help students recognize the way of thinking employed in science and how this thinking may be similar to, and different from, the ways of thinking that are useful in other parts of their lives. 
We suggest that the traditional focus on the scientific method should be replaced with a focus on science as a way of knowing (Moore, 1999), and this is particularly important in an equitable science classroom that recognizes students' religious faith. With science as a way of knowing, Moore described science as embracing particular assumptions and characteristics that set it apart from other ways of knowing the world. Assumptions of the culture of science include that the most scientific explanations are always logical, simple, and straightforward, and do not employ supernatural forces or agents. In part because of these assumptions, the characteristics of scientific knowledge include that science is empirical, tentative, and bounded. Thus, to gain the power of a scientific theory to explain, predict, and solve specific puzzles/problems, one also must consider the boundedness engendered by the theory. Indeed, although the characteristics of science and the assumptions underlying those inquiries make science such a powerful way of knowing the world, these assumptions of the action of science also place boundaries around what can be understood scientifically.

An emphasis on science as a way of knowing acknowledges that science is simply one way of knowing our world, a way that is bounded by its requirement of empirical evidence and a rejection of explanations relying on supernatural causality. These assumptions and characteristics distinguish science from other ways of knowing the world, ways such as the artistic with standards that do not require logic, evidence or reason; the philosophical with standards of logic and reason quite different from the scientific; and traditional belief systems with assumptions, such as the religious presumption of supernatural agents, in direct conflict with those of science.

It is important to emphasize that there is no implied hierarchy to these ways of knowing. Rather, teachers should highlight that humans rely upon a range of strategies for understanding their world. Students employ the products of scientific thought as they take medicine, ride in cars, and use computers. We live complex lives and science has proven to be very useful to answer some questions in those lives. However, it is also important to highlight that there are circumstances where science is of little use. Humans rely upon other ways of knowing that operate under different assumptions and have different characteristics-the aesthetic, kinesthetic, religious, interpersonal, and the deeply personal. 
What an Explicit Consideration of the Boundaries of Science Allows

We are suggesting that it is important for students to understand that science as a way of knowing is very helpful in understanding some aspects of their lives, but nearly useless for other aspects. Although some individuals and groups suggest that science refutes other ways of knowing, this view is based on the claim that science is the only way of knowing the world. Smith and Scharmann (1999) suggested that it is valuable for teachers to describe that science does not assert that there are no supernatural forces, and it does not refute the existence of God. Instead, science refuses to invoke supernatural or metaphysical explanations in constructing knowledge-as scientific explanations must rely on logic, observable evidence, patterns that can be independently inferred from observable data, and testing. That science does not use the supernatural in its work does not suggest that the supernatural does not exist-just that the use of the supernatural in constructing an explanation makes that explanation nonscientific. Not wrong, just not science. This is a crucial distinction. Simply because an explanation is not scientific does not necessarily make it a weak or flawed explanation, but simply nonscientific. That same nonscientific explanation may be useful for a great number of people to make sense of their lives, but that explanation is simply not scientific.

We have argued elsewhere that by showing students the boundaries of scientific thought and explanations-by emphasizing that although science has provided incredibly productive explanations of the natural world and that it does not provide the only explanations that have importance to people-educators provide students with a "place to stand" when confronted with a seeming conflict between scientific knowledge and religious beliefs (Scharmann, 1990, p. 98). This "place to stand" provides needed emotional room for students to come to understand science (and its theories) as a powerful set of tools that offer explanations. Students must then individually determine how this knowledge fits in with their own ways of understanding the natural world. 
What Is Not Done in This Explicit Consideration

It is important to recognize what an equitable approach includes and does not include. Proponents of curricular multicultural science education (MSE) describe that to be sensitive to students' knowledge and beliefs that are counter to science, one must redefine one's conceptions of science. Curricular MSE often equates local or ethnic ways of understanding the physical world with that of science. In contrast, instructional MSE describes how to craft instruction to effectively teach science as it is traditionally defined while respecting student beliefs. Although both curricular and instructional MSE have the goal of engaging students in science, they work to achieve this goal in fundamentally different ways-one is to redefine science to be more inclusive of students' beliefs, and the other is to make students aware of the epistemology of traditional science and decide for themselves when it is appropriate to invoke that epistemology. Our proposal, that of making students aware of the bounded nature of science, is out of the tradition of instructional MSE-it emphasizes the need for students to understand the habits of mind employed in science if they are to successfully (and selectively) use those habits themselves.

\section{Biological Evolution as an Example of Equitable Science Education}

Our own work at the intersection of science and religious beliefs has been in evolution education, where there is a growing body of both curriculum development and research. This area of scholarship supports an explicit and reflective consideration of the epistemological foundations of science as a central aspect of any science classroom, and particularly an equitable science classroom (Southerland et al., 2011). Although this goal may sound daunting to a novice (or even to a veteran) teacher, there is a wealth of appropriate curricula to support the teaching of epistemological foundations of science in the K-12 science classroom (Bell, 2007; National Academy of Sciences, 1998, 2008).

Smith and Scharmann (2008) suggested that it is helpful for teachers to consider school science as a culture that is different from students' out-of-school lives. When this school culture is perceived to conflict with their religious beliefs, students may consider science to be personally threatening: 
Too little attention has been paid to the need for an appreciation that students with radically different views of the nature of science (often concomitant with strongly held conservative religious beliefs) might best be viewed as citizens of radically disparate countries with diametrically opposed worldviews (Cobern, 1991). For many of these individuals, merely considering an attempt to understand the basic tenets of theories held by "the other camp" is asking that student to "cross a border" that is greatly feared (Aikenhead \& Jegede, 1999). Persons crossing that border may not only risk the loss of personal identity but may also risk becoming a traitor to oneself and the people they love. This is indeed much to ask of a student who must spend the rest of his life in that world outside the classroom. (p. 25)

Certainly, a classroom where students are worried about this intellectual and cultural conflict is not an atmosphere conducive to learning. In recognition of the emotional turmoil one might experience, an early, explicit consideration of the nature of scientific knowledge with a particular focus on the boundaries of science can prove useful.

As an example of what such consideration may look like, Smith and Scharmann (1999) described that teachers can present a number of questions and then facilitate a discussion of how to place these questions on a continuum between more and less scientific. This list may include questions such as: Is it wrong to keep porpoises in captivity? How was the Earth made? Do ghosts haunt old houses at night? Am I in love? Is there a god? Through discussion, students begin to recognize what science is particularly good at understanding and what is clearly out of the scope of scientific investigation. Once we begin this conversation in the classroom, we begin to understand that there are many important aspects of our lives that are out of the boundaries of scientific investigation (religious beliefs, interpersonal relationships, morality), because they rely on the supernatural or metaphysical or because they are not empirical. Students can clearly understand that just because these things are out of the bounds of science does not prevent them from playing a huge part in our lives.

Smith and Scharmann (2008) provided descriptions of additional activities in which students can be supported in constructing a 
relatively sophisticated understanding of the nature and characteristics of science through a carefully crafted sequence of activities that allow them to examine examples and nonexamples of science, what Thomas Kuhn described as learning by ostention. The central concept of this approach is that children learn most effectively through exposure to examples within a category, not by memorizing the characteristics of a category. Thus, Smith and Scharmann suggest that science classes should include an early unit focusing on the nature of science knowledge in which students focus first on prototypical examples and counterexamples, employing contrasting sets of these examples, and sequencing these examples from most prototypical to borderline cases. This sequence includes an activity that requires students to place evolution, intelligent design, and umbrellaology along a lessto-more scientific continuum and then to justify in writing their decisions, based on accepted criteria. Through this approach, students begin to understand the characteristics of science, as well as become more experienced in examining the characteristics of a knowledge claim. Of primary importance is putting students at ease throughout such discussions.

\section{Conclusion}

Although not usually a topic when discussing issues of teaching science to diverse learners, we have argued that an equitable approach to science must also be cognizant of students' religious beliefs. We propose that such an approach should include the explicit portrayal of science as a form of human understanding that is useful and rational, but also bounded. In equitable classrooms, students will become familiar with the fundamental differences that exist among various systems of thought (such as science, art, literature, and religion), as well as the strengths of each of these as human enterprises for promoting understanding. In an equitable science classroom, students are guided to understand the unique characteristics of scientific thought along with its limits, allowing them to select when to use a scientific approach to a question or problem/ puzzle, and when another way of knowing may be as or more useful. Through such an approach, students come to understand that science is one powerful way of understanding the world, but not the only way. This explicit 
emphasis on epistemology gives students who hold religious beliefs counter to mainstream science the emotional room to understand science, to examine the value that they place upon a knowledge claim, and to understand why they place such value. In such classrooms, students are taught to deliberate and examine a knowledge claim to determine the degree to which it conforms to the assumptions and characteristics of science, and then to decide how this knowledge fits within their own understanding of the natural world. An equitable approach to the teaching of science replaces the presumption of acceptance with understanding and transforms attempted indoctrination with informed deliberation.

\section{References}

Aguillard, D. (1999). Evolution education in Louisiana public schools: A decade following Edwards v Aguillard. American Biology Teacher, 61, 182-188.

Aikenhead, G. S., \& Jegede, O. J. (1999). Cross-cultural science education: A cognitive explanation of a cultural phenomenon. Journal of Research in Science Teaching, 36, 269-287.

Alters, B. J., \& Alters, S. M. (2001). Defending evolution: A guide to the creation/ evolution controversy. Sudbury, MA: Jones \& Bartlett.

Bell, R. (2007). Teaching the nature of science through process skills: Activities for grades 3-8. New York, NY: Allyn \& Bacon.

Cobern, W. W. (1991). World view theory and science education research (NARST Monograph No. 3). Manhattan, KS: National Association for Research in Science Teaching.

Cochran-Smith, M. (1995). Colorblindness and basket making are not the answers: Confronting the dilemmas of race, culture, and language diversity in teacher education. American Educational Research Journal, 32, 493-522.

Dean, C. (2005, February 1). Evolution takes a back seat in U.S. classes. The New York Times, Section F, p. 1.

Kuhn, T. (1962). The structure of scientific revolutions. Chicago, IL: University of Chicago Press.

Moje, E. B., Collazo, T., Carrillo, R., \& Marx, R. W. (2001). "Maestro, what is quality?”: Language, literacy, and discourse in project-based science. Journal of Research in Science Teaching, 38, 469-496.

Moore, J. (1999). Science as a way of knowing. Harvard, MA: Harvard University Press.

Nadelson, L. A., \& Southerland, S. A. (2010). Examining the interaction of acceptance and understanding: How does the relationship change with a focus on macroevolution? Evolution: Education and Outreach, 3, 84-92. 
National Academy of Sciences. (2008). Science, evolution and creationism. Washington, DC; National Academy Press.

National Academy of Sciences. (1998). Teaching about evolution and the nature of science. Washington, DC: National Academy Press.

No Child Left Behind Act of 2001, Pub. L. No. 107-110, 115 Stat. 1425 (2002).

Retrieved April 19, 2012 from http://www.ed.gov/legislation/ESEA02/

Pew Research Center. (2008). U.S. religious landscape Survey Religious Affiliation: Diverse and dynamic. Washington, DC: Author. Retrieved from http://religions. pewforum.org/reports

Scharmann, L. C. (1990). Enhancing an understanding of the premises of evolutionary theory: The influence of a diversified instructional strategy. School Science and Mathematics, 90, 91-100.

Scott, E., \& Branch, G. (Eds.). (2006). Not in our classrooms: Why intelligent design is wrong for our schools. New York, NY: Beacon Press.

Smith, M. U., \& Scharmann, L. C. (2008). A multiyear program developing an explicit reflective pedagogy for teaching preservice teachers the nature of science by ostention. Science and Education, 17, 219-248.

Smith, M., \& Scharmann, L. (1999). Describing versus defining the nature of science. Science Education, 83, 493-509.

Southerland, S. A., Gallard, A., \& Callahan L. (2011). Teachers' hurdles to science for all. International Journal of Science Education, 33(16), 2183-2213.

Southerland, S. A., Golden, B., \& Enderle, P. (2011). The bounded nature of science: An effective tool in an equitable approach to the teaching of science. In M. Y. Khine (Ed.), Advances in the Nature of Science Research: Concepts and Methodologies, chapter 4. Dordrecht, Netherlands: Springer.

Southerland, S. A., Smith, L. K., Sowell, S., \& Kittleson, J. (2007). Resisting unlearning: Understanding science education's response to the United States' national accountability movement. Review of Research in Education, 31, 45-77. 